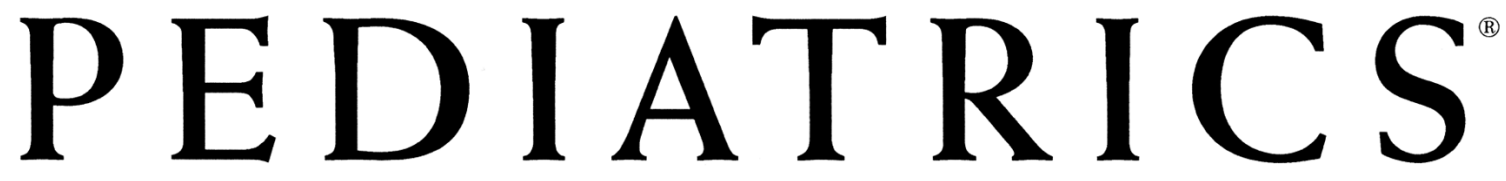

OFFICIAL JOURNAL OF THE AMERICAN ACADEMY OF PEDIATRICS

\title{
A Parent-Led Family-Focused Treatment Program for Overweight Children Aged 5 to 9 Years: The PEACH RCT
}

Anthea M. Magarey, Rebecca A. Perry, Louise A. Baur, Katharine S. Steinbeck, Michael Sawyer, Andrew P. Hills, Gizelle Wilson, Anthea Lee and Lynne A. Daniels Pediatrics 2011;127;214; originally published online January 24, 2011;

DOI: $10.1542 /$ peds.2009-1432

The online version of this article, along with updated information and services, is located on the World Wide Web at: http://pediatrics.aappublications.org/content/127/2/214.full.html

PEDIATRICS is the official journal of the American Academy of Pediatrics. A monthly publication, it has been published continuously since 1948. PEDIATRICS is owned, published, and trademarked by the American Academy of Pediatrics, 141 Northwest Point Boulevard, Elk Grove Village, Illinois, 60007. Copyright (? 2011 by the American Academy of Pediatrics. All rights reserved. Print ISSN: 0031-4005. Online ISSN: 1098-4275.

\section{American Academy of Pediatrics}




\section{A Parent-Led Family-Focused Treatment Program for Overweight Children Aged 5 to 9 Years: The PEACH RCT}

\begin{abstract}
WHAT'S KNOWN ON THIS SUBJECT: For treatment of obesity in preadolescent children, approaches that focus on parents taking sole responsibility for implementing weight-management strategies may be most effective. However, the optimal content, intensity, and duration of programs for obese children remain unclear.
\end{abstract}

WHAT THIS STUDY ADDS: Targeting parents only, a 10\% relative weight loss is achievable in moderately obese preadolescent children and can be maintained 2 years from baseline, which justifies an investment in treatment as a secondary obesityprevention strategy.

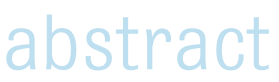

OBJECTIVE: To evaluate a healthy lifestyle intervention to reduce adiposity in children aged 5 to 9 years and assess whether adding parenting skills training would enhance this effect.

PARTICIPANTS AND METHODS: We conducted a single-blinded randomized controlled trial of prepubertal moderately obese (International Obesity Task Force cut points) children, aged 5 to 9 years. The 6-month program targeted parents as the agents of change for implementing family lifestyle changes. Only parents attended group sessions. We measured BMl and waist $z$ scores and parenting constructs at baseline, 6, 12, 18, 24 months.

RESULTS: Participants ( $n=169 ; 56 \%$ girls) were randomized to a parenting skills plus healthy lifestyle group $(n=85)$ or a healthy lifestyle-only group $(n=84)$. At final 24 -month assessment 52 and 54 children remained in the parenting skills plus healthy lifestyle and the healthy lifestyle-only groups respectively. There were reductions ( $P<$ $.001)$ in BMl $z$ score (0.26 [95\% confidence interval: $0.22-0.30])$ and waist $z$ score ( 0.33 [ $95 \%$ confidence interval: $0.26-0.40]$ ). There was a $10 \%$ reduction in $z$ scores from baseline to 6 months that was maintained to 24 months with no additional intervention. Overall, there was no significant group effect. A similar pattern of initial improvement followed by stability was observed for parenting outcomes and no group effect.

CONCLUSIONS: Using approaches that specifically target parent behavior, relative weight loss of $\sim 10 \%$ is achievable in moderately obese prepubertal children and can be maintained for 2 years from baseline. These results justify an investment in treatment as an effective secondary obesity-prevention strategy. Pediatrics 2011;127:214-222
AUTHORS: Anthea M. Magarey, PhD, ${ }^{a}$ Rebecca A. Perry, PhD, BHSc, a Louise A. Baur, MBBS, BSc(Med), PhD, FRACP, Katharine S. Steinbeck, MBBS, PhD, FRACP, ${ }^{c}$ Michael Sawyer, MBBS, PhD, FRCPC, FRANZCP, ${ }^{d}$ Andrew P. Hills, BEd, MSc, PhD, e Gizelle Wilson, BN, ${ }^{a}$ Anthea Lee, MND, ${ }^{b}$ and Lynne A. Daniels, PhD, MSc ${ }^{e}$

aDepartment of Nutrition and Dietetics, Flinders University, Adelaide, Australia; ${ }^{b}$ Discipline of Paediatrics and Child Health, University of Sydney, Children's Hospital at Westmead, Westmead, New South Wales, Australia; 'Academic Department of Adolescent Medicine, University of Sydney School of Medicine, Sydney, Australia; ${ }^{d}$ Discipline of Paediatrics, University of Adelaide, Adelaide, Australia; and ${ }^{e}$ Institute of Health and Biomedical Innovation, Schools of Public Health and Human Movement Studies, Queensland University of Technology, Queensland, Australia

KEY WORDS

child, obesity, treatment, parenting, BMI, waist circumference ABBREVIATIONS

PEACH_Parenting Eating and Activity for Child Health $\mathrm{HL}$-healthy lifestyle education without specific parenting skills training intervention

$\mathrm{P}+\mathrm{HL}$ - healthy lifestyle education with parenting skills training intervention

This trial has been registered at the Australian Clinical Trials Register (www.actr.org.au) (identifier 00001104)

www.pediatrics.org/cgi/doi/10.1542/peds.2009-1432

doi:10.1542/peds.2009-1432

Accepted for publication Nov 12, 2010

Address correspondence to Anthea M. Magarey, PhD, Department of Nutrition and Dietetics, Flinders University, GP0 Box 2100, Adelaide 5001, Australia. E-mail: anthea.magarey@ flinders.edu.au

PEDIATRICS (ISSN Numbers: Print, 0031-4005; Online, 1098-4275) Copyright $\odot 2011$ by the American Academy of Pediatrics FINANCIAL DISCLOSURE: The authors have indicated that they have no personal financial relationships relevant to this article to disclose. 
In most developed countries, $20 \%$ to $30 \%$ of children are overweight, 1,2 with immediate health and psychosocial consequences and increased risk of adult obesity. ${ }^{3}$ Effective treatment is required and constitutes an important secondary prevention strategy. ${ }^{4}$ However, good-quality studies evaluating the effectiveness of treatment programs are scarce. ${ }^{5}$

The cornerstones of child weight management are diet and activity changes through behavior modification with parental involvement and support. ${ }^{6-8}$ The studies of Golan et al ${ }^{9,10}$ support the use of parents as the exclusive "agents of change" responsible for implementing weight-management strategies. They demonstrated better outcomes when parents alone were targeted and children not included in intervention sessions. ${ }^{9}$ For prepubertal children, this approach is developmentally appropriate, focuses on family lifestyle, and avoids stigmatizing the overweight child. However, Golan et al's studies have not been replicated in other populations, ${ }^{11}$ and evidence for how best to support parents in this role is limited. ${ }^{12}$

Parenting styles can be defined on the dimensions of behavioral control and responsiveness (warmth) and have been associated with child weight status. ${ }^{13}$ Children exposed to authoritative parenting (high control and warmth) at 4 to 5 years of age are likely to eat more vegetables ${ }^{14}$ and 5 times less likely to be overweight at 7 years of age ${ }^{15}$ than children who experience authoritarian (high control, low responsiveness) parenting. A review of familybased interventions for pediatric obesity identified 6 of 31 programs in which the intervention included a general parenting training component. ${ }^{12}$ All programs involved children directly in the intervention and produced mixed results. Providing parenting skills training has the theoretical potential to modify parenting style and equip parents for a "changeagent" role and, hence, is a plausible means of enhancing the effectiveness of traditional approaches to weight management.

The aims of this study were to evaluate (1) the effectiveness of a healthy lifestyle intervention for overweight children aged 5 to 9 years that targets parents as the agents of change and (2) whether additional specific parenting skills training would improve parenting skills and enhance the intervention effect. The long-term effect (2 years from baseline) and the immediate postintervention effect (at completion of the intervention, 6 months from baseline) were assessed. We also aimed to confirm gender differences reported in our previous study. ${ }^{16}$

\section{METHODS}

\section{Participants}

Families were recruited between May 2004 and March 2005 via media publicity and school newsletters in 2 Australian cities: Adelaide and Sydney. Inclusion criteria were being age 5.0 to 9.9 years, being overweight (International Obesity Task Force definition) ${ }^{17}$ and prepubertal (Tanner stage 1), ${ }^{18}$ having a caregiver willing to attend sessions, and being able to speak English. Exclusion criteria were having a BMI z score of $>4.0$, having a syndromal cause of obesity, using medications that influence weight, having a physical or developmental disability, having a chronic illness, or having a sibling enrolled in the study. Eligibility was assessed via telephone and confirmed by medical examination.

\section{Study Design}

A single-blinded randomized controlled trial compared the effectiveness of 2 interventions: the healthy lifestyle education with parenting skills training intervention ( $\mathrm{P}+\mathrm{HL}$ group) or the healthy lifestyle education without specific parenting skills training intervention (HL group). The study was conducted at Flinders Medical Centre (Adelaide, South Australia) and at the Children's Hospital at Westmead (Sydney, New South Wales, Australia) and was approved by both hospitals' ethics committees. The study was named Parenting Eating and Activity for Child Health (PEACH) and was registered with the Australian Clinical Trials Register. The design, conduct, and reporting of this study complied with the CONSORT (Consolidated Standards of Reporting Trials) statement. ${ }^{19}$

After baseline measurements, participants were allocated to intervention groups using computer-generated randomization schedules stratified according to gender and recruitment site and prepared by staff not otherwise involved in the study. Allocation was concealed in opaque, sequentially numbered, sealed envelopes and opened by parents after completion of baseline measurements.

\section{Treatment Components}

All $\mathrm{P}+\mathrm{HL}$ sessions at each site were conducted by the same dietitian (Drs Perry and Lee), after accredited training for the parenting skills component. The HL sessions were conducted by 1 dietitian in Adelaide and 2 in Sydney, none of whom had undergone parenting skills training. A parent-only approach ${ }^{20,21}$ was used for both groups, with only parents attending education sessions and being held solely responsible for implementing family lifestyle changes. Children did not attend any intervention sessions. The P+HL sessions encouraged parents to anticipate and manage high-risk situations with respect to a positive energy balance, using a problem-solving approach. HL sessions focused on information only, consistent with traditional nutrition and clinical advice approaches. All sessions were audiotaped and inde- 
pendently audited to confirm program fidelity, particularly maintenance of planned differences between the $\mathrm{P}+\mathrm{HL}$ and $\mathrm{HL}$ interventions.

The interventions included $12(\mathrm{P}+\mathrm{HL}$ group) or 8 (HL group) 90- to 120minute group sessions (open to both parents but mostly attended by mothers) and 4 telephone sessions, delivered over 6 months with tapered frequency (weekly, bimonthly, then monthly). Details of the standardized parenting skills program ${ }^{22}$ and the healthy lifestyle education sessions have been reported previously. ${ }^{21}$ Briefly, the Positive Parenting Program (Triple P [Families International, Health Department, University of Queensland, Queensland, Western Australia, 2000]; see www.triplep.net) was delivered in 4 sessions to $\mathrm{P}+\mathrm{HL}$ parents before the lifestyle $(\mathrm{HL})$ component. It is a standardized and evaluated generic parenting program widely used in Australia and provides comprehensive facilitator training. ${ }^{22}$ The $8 \mathrm{HL}$ sessions included recommendations on specific core food servings; practical skills for healthy eating, reduced sedentary behaviors, and increased activity; and monitoring of lifestyle behaviors and roles and responsibilities around eating, managing appetite, self-esteem, and teasing. ${ }^{21}$ The 4 telephone sessions alternated with the last 4 group sessions for both arms, using a standard protocol. Although parents attended intervention sessions, children and siblings participated in fun, noncompetitive activity sessions run by physical activity educators. These sessions provided optional active child care for participants in both groups and were not part of the intervention. Three cohorts of $\sim 28$ families (14 per group) participated at each site.

\section{Measurements}

Outcomes were assessed at baseline, immediately postintervention (6 months), and at 12, 18, and 24 months. Measurements were taken by the same trained blinded assessors who were independent of intervention delivery.

At baseline, a 33-item questionnaire addressed family demographics and parent and child health status. Socioeconomic status was determined using the Socio Economic Index for Areas, in which low scores indicate relative disadvantage. The index is standardized to have a mean of $1000 \pm 100$, and $95 \%$ of index scores fell between 800 and $1200 .^{23}$

The primary outcome was BMI $z$ score. Height, weight, and waist circumference were measured using standard anthropometric methods. ${ }^{24} \mathrm{BMI}$ and waist circumference $z$ scores were calculated using the 1990 United Kingdom reference data (United Kingdom Child Growth Foundation LMS software). ${ }^{25,26}$ Child weight status was determined using the International Obesity Task Force definition. ${ }^{17}$ Program impact was evaluated using (1) the Parenting Sense of Competence Scale, ${ }^{27}$ which assesses parental competency via a parent's satisfaction with their parental role (9 items) and their feelings of efficacy (7 items) as a parent (internal consistency, satisfaction, efficacy, total score $\alpha=.75, .76$, and .79, respectively) ${ }^{27}$; and (2) the Alabama Parenting Questionnaire, which measures 5 parental constructs: involvement with child (10 items $[\alpha=$ $.80]$ ), use of positive parenting ( 6 items $[\alpha=.80]$ ), monitoring and supervision (10 items $[\alpha=.67]$ ), consistency in applying discipline $(6$ items $[\alpha=$ $.67])$, and corporal punishment practices (3 items $[\alpha=.46]$ ). ${ }^{28}$

\section{Statistical Analysis}

Analyses were performed by using SPSS 17.0 for Windows (SPSS Inc, Chicago, IL). Our sample size calculation was based on a reduction in BMI $z$ score of $0.26 \pm 0.49$ over 12 months (consistent with the Cochrane review) ${ }^{29}$ (power $80 \%, \alpha=.05$, and dropout rate of $30 \%$ ). This represents a $50 \%$ reduction in weight velocity over 12 months and no change in height velocity. ${ }^{30}$ We sought 42 children per group per site $(n=168)$. Normally distributed variables are reported as means $\pm S D$ and proportions. Intention-to-treat analysis was conducted using all available data according to allocation, regardless of attendance. Linear mixed models (SPSS mixed) using first-order autoregressive structure, including time (as repeated factor), group, gender, and site and their interactions, with Bonferroni correction for posthoc multiple comparisons, were used. ${ }^{31,32}$ The estimated means \pm SEM were plotted. To enable reporting of relative effect size, percentage change in $z$ score from 0 to 6 months was determined using paired $t$ tests. A similar linear mixed-model analysis was performed for each of the parenting outcomes. A second perprotocol analysis was performed that included only those who attended $75 \%$ or more of the program sessions. The potential effect of missing data were explored using $t$ tests to compare the baseline and 6-month BMI $z$ scores of those who remained and those who were lost to follow-up. ${ }^{33}$

\section{RESULTS}

\section{The Sample}

Participant flow and characteristics at baseline are shown in Fig 1 and Table 1. At baseline, $22 \%$ of children were overweight and $78 \%$ were obese. Most children (74\%) were from dual-parent families, and $73 \%$ of parents were Australian born. The mean Socio Economic Index for Areas was higher for participants from Sydney $(1055 \pm 80)$ than participants from Adelaide ( $999 \pm 66$ ) but was consistent with the state of residence. There were no significant differences according to allocation group at baseline $(P>40)$. Boys had higher baseline BMI and waist $z$ scores than girls ( $P<.001$ both), and partici- 


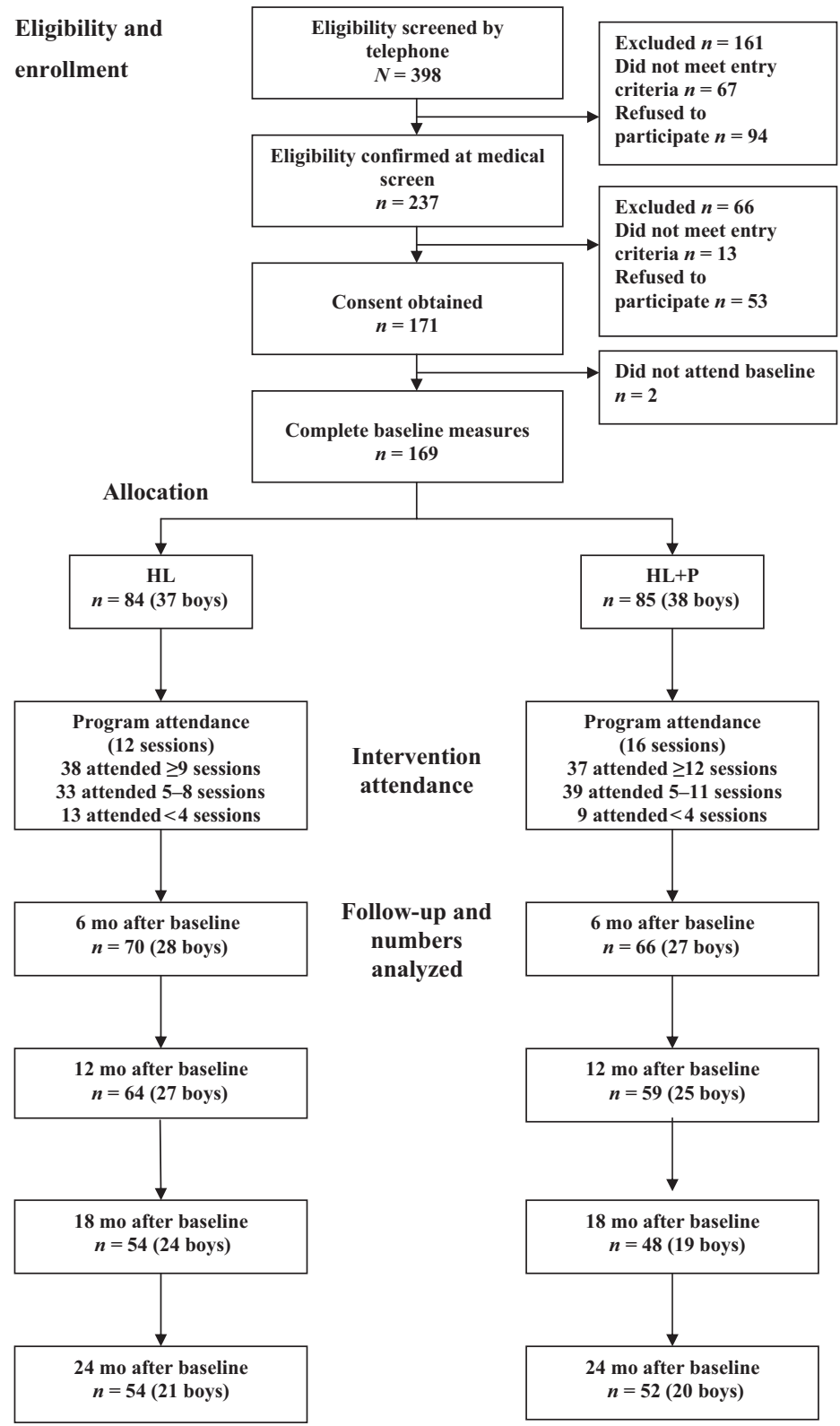

FIGURE 1

Participant flow through the study.

TABLE 1 Baseline Anthropometric Measurements (Mean \pm SD) for 5- to 9-Year-0ld Prepubertal Children Enrolled in the PEACH Study

\begin{tabular}{|c|c|c|c|c|}
\hline & All & Boys & Girls & $p a$ \\
\hline$n$ & 169 & 74 & 95 & - \\
\hline Age, y & $8.2+1.2$ & $8.3 \pm 1.2$ & $8.1 \pm 1.2$ & .29 \\
\hline Height, cm & $135.3 \pm 9.2$ & $136.9 \pm 9.8$ & $133.6 \pm 8.4$ & .02 \\
\hline Height $z$ score ${ }^{b}$ & $1.22 \pm 0.95$ & $1.38 \pm 0.99$ & $1.10 \pm 0.91$ & .06 \\
\hline Weight, kg & $44.4 \pm 9.82$ & $46.3 \pm 10.2$ & $42.9 \pm 9.3$ & .02 \\
\hline BMI & $24.1 \pm 3.22$ & $24.5 \pm 3.2$ & $23.8 \pm 3.2$ & .16 \\
\hline BMl $z$ score ${ }^{b}$ & $2.72 \pm 0.62$ & $2.95 \pm 0.52$ & $2.54 \pm 0.63$ & $<.001$ \\
\hline Waist circumference, $\mathrm{cm}$ & $77.1 \pm 8.62$ & $79.3 \pm 8.6$ & $75.5 \pm 8.3$ & .004 \\
\hline Waist circumference $z$ score ${ }^{b}$ & $3.11 \pm 0.63$ & $3.31 \pm 0.62$ & $2.95 \pm 0.59$ & $<.001$ \\
\hline
\end{tabular}

a Independent $t$ test for differences according to gender.

${ }^{\mathrm{b}}$ Calculated by comparing participant values against UK reference-population data. 2.233 pants from Sydney had higher baseline BMI $(P<.001)$ and waist $z$ scores $(P=$ $.02)$ than participants from Adelaide.

Table 2 presents the mean (SD) for BMI and waist $z$ scores at each time for all participants and according to group, and Fig 2 presents the estimated means (SEM) derived from the mixedmodel analysis.

\section{Anthropometric Outcomes}

There was a significant time effect for both $\mathrm{BMI}$ and waist circumference $z$ scores (linear mixed model $P<.001$ for both). Values at each of the 4 assessments postintervention (6-24 months) were less than baseline, but there were no differences between these 4 points (ie, there was an immediate intervention effect that was maintained over the subsequent 18 months). There was no group effect for either BMI $(P=.88)$ or waist $(P=.93)$ $z$ scores or any group-by-time or group-by-site interactions. By far, the greatest change in relative weight occurred between baseline and 6 months followed by 18 months. The immediate postintervention (6 months) decrease in BMI $z$ score was 0.26 (95\% confidence interval [CI]: $0.20-0.31$ ) or $10 \%$ (range: $-22 \%$ to $60 \%$ ) and in waist circumference z score 0.34 (95\% Cl: $0.20-$ 0.48 ) or $10 \%$ (range: $-29 \%$ to $74 \%$ ).

For BMI $z$ score only, there was a significant gender effect; boys had higher values than girls $(P<.001)$. There was no time-by-gender interaction, which indicates that changes over time were no different according to gender, and the difference reflects the baseline difference. In contrast, there was no gender effect for waist $z$ score $(P=.06)$ but a significant time-by-gender interaction $(P=.005)$, and there was a greater decrease in boys compared with girls. The reductions by gender for BMl z score were 0.31 (95\% Cl: 0.250.38 ) or $12 \%$ (range: $-5 \%$ to $45 \%$ ) in boys and 0.22 ( $95 \% \mathrm{Cl}: 0.16-0.27$ ) or 
TABLE 2 BMl and Waist $z$ Scores at Each Assessment and Stability of Overweight at 6 Months of Children Aged 5 to 9 Years Enrolled in the PEACH Study, According to Allocated Treatment Group (P+HL or HL)

\begin{tabular}{|c|c|c|c|c|c|c|}
\hline & \multicolumn{3}{|c|}{$\mathrm{BMI} z$ Score, Mean $\pm \mathrm{SD}(n)^{\mathrm{a}, \mathrm{b}}$} & \multicolumn{3}{|c|}{ Waist $z$ Score, Mean $\pm S D(n)^{a, c}$} \\
\hline & All & $\mathrm{P}+\mathrm{HL}$ & $\mathrm{HL}$ & All & $\mathrm{P}+\mathrm{HL}$ & $\mathrm{HL}$ \\
\hline Baseline & $2.72 \pm 0.62(169)$ & $2.77 \pm 0.58(85)$ & $2.68 \pm 0.65(84)$ & $3.11 \pm 0.63(168)$ & $3.13 \pm 0.59(84)$ & $3.09 \pm 0.67(84)$ \\
\hline $6 \mathrm{mo}$ & $2.47 \pm 0.70(135)$ & $2.48 \pm 0.70(66)$ & $2.46 \pm 0.70(69)$ & $2.78 \pm 0.69(136)$ & $2.79 \pm 0.67(66)$ & $2.76 \pm 0.71(70)$ \\
\hline $12 \mathrm{mo}$ & $2.45 \pm 0.68(123)$ & $2.46 \pm 0.65(59)$ & $2.44 \pm 0.71(64)$ & $2.76 \pm 0.70(122)$ & $2.77 \pm 0.67(58)$ & $2.75 \pm 0.74(64)$ \\
\hline $18 \mathrm{mo}$ & $2.43 \pm 0.72(102)$ & $2.46 \pm 0.70(48)$ & $2.39 \pm 0.75(54)$ & $2.82 \pm 0.71(102)$ & $2.83 \pm 0.61(48)$ & $2.81 \pm 0.80(54$ \\
\hline $24 \mathrm{mo}$ & $2.32 \pm 0.76(106)$ & $2.38 \pm 0.67(52)$ & $2.26 \pm 0.84(54)$ & $2.69 \pm 0.77(105)$ & 2. $66 \pm 0.62(52)$ & $2.72 \pm 0.89(53)$ \\
\hline $\begin{array}{l}z \text {-score change at } \\
0-6 \text { mo }(x: y: z)^{d}\end{array}$ & - & $58: 1: 7$ & $57: 2: 10$ & & $53: 0: 12$ & $52: 1: 16$ \\
\hline
\end{tabular}

a $Z$ scores were calculated by comparing participant values against UK reference-population data. ${ }^{19,20}$

b Linear mixed model: $P<.001$ time, $P=.88$ group, $P=.17$ group by time, $P<.001$ gender, $P=.004$ site, and covariate baseline age $=8.12$.

${ }^{\mathrm{c}}$ Linear mixed model: $P<.001$ time, $P=.93$ group, $P=.73$ group by time, $P=.06$ gender, $P=.005$ gender by time, and covariate baseline age $=8.11$

d Number of participants: $x$, reducing $z$ score; $y$, stable; $z$ : increasing.

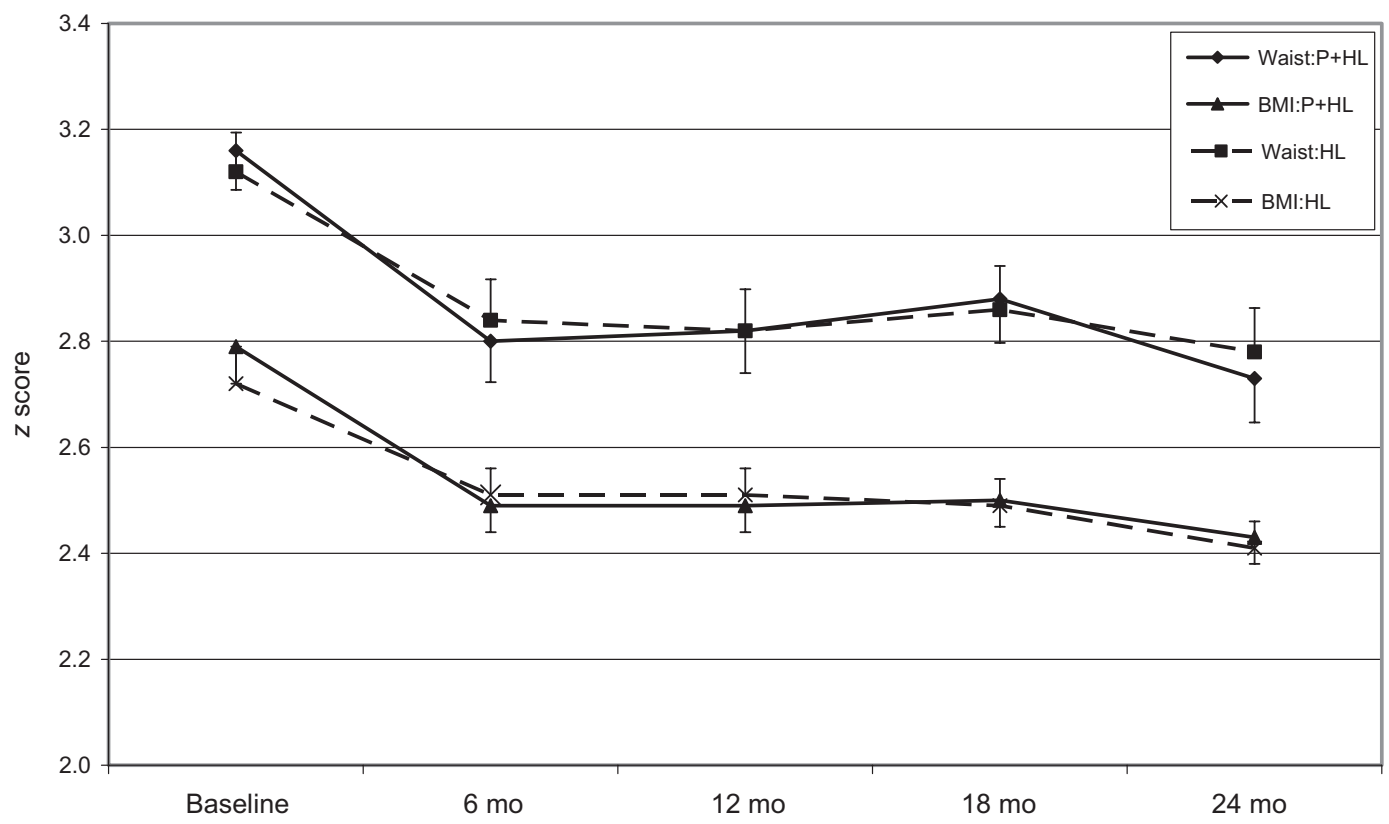

FIGURE 2

BMI and waist $z$ scores (adjusted mean \pm SEM) according to allocated treatment group (P+HL or HL) in overweight children aged 5 to 9 years $(n=169$ at baseline). Linear mixed model: BMI and waist circumference $z$ scores, main effect of time $P<.001$, posthoc analysis (Bonferroni method) $P<.001$ for baseline versus all other times. $P$ was not significant for main effect of group and group-by-time interaction.

9\% (range: $-22 \%$ to $60 \%$ ) in girls, and for waist $z$ score the reductions were 0.44 (95\% Cl: $0.33-54$ ) or $14 \%$ (range: $-9 \%$ to $47 \%$ ) in boys and $0.21(95 \% \mathrm{Cl}$ : $0.12-0.30$ ) or $7 \%$ (range: $-29 \%$ to $74 \%)$ in girls. There was a significant site effect for BMl $z$ score only ( $P=$ .004), reflecting the higher baseline values in Sydney compared with Adelaide.

The stability from 6 to 18 months of the $z$ scores shown above influences the overall model and potentially disguises any weak group difference that may exist at 6 months (intervention end). A second model that included only the first 2 time points showed no group effect, but there was a weak group-by-time interaction ( $P=.034$ ) for $\mathrm{BMI} z$ score only, with a reduction in $\mathrm{P}+\mathrm{HL}$ of 0.36 (95\% Cl: $0.26-0.45$ ) and a decrease of $12 \%$ (range: $-12 \%$ to $56 \%)$ and a reduction in $\mathrm{HL}$ of $0.30(95 \%$ Cl: $0.20-0.39$ ) and a decrease of $8 \%$ (range: $-21 \%$ to $53 \%$ ). The frequency of increasing, maintaining, or decreasing BMI or waist $z$ score at 6 months according to group is shown in Table 2.
Mixed-model analysis assumes that missingness is random. A comparison of available BMI $z$ scores of those remaining in the study and those lost to follow-up at each point identified a tendency for those lost to follow-up, particularly in the HL group, to have a greater BMI $z$ score at the last measurement than those remaining in the study. For example, the baseline BMI $z$ score of those remaining at 6 months compared with those not remaining was higher in $\mathrm{P}+\mathrm{HL}(0.14 \pm 0.16)$ and lower in $\mathrm{HL}(-0.22 \pm 0.24)$ subjects 
(neither significant); the 6-month BMI $z$ score of those remaining to 24 months and those lost to follow-up at any point after 6 months was lower in both the $\mathrm{P}+\mathrm{HL}(-0.05 \pm 0.13$; $P$ was not significant) and $\mathrm{HL}(-0.24 \pm 0.12 ; P=.05)$ groups. The greater differences in the HL group suggest an attrition bias that favors the more overweight participants in the HL group.

\section{Per-Protocol Analysis}

Seventy-five parents (27 with boys) attended at least $75 \%$ of the scheduled sessions. The intervention effect for BMl $z$ score, time $(P<.001)$, and site $(P=.002)$ remained significant; gender was no longer significant, but there was a significant gender-by-time interaction $(P=.03)$. For waist zscore, time $(P<.001)$ and gender-by-time $(P=.05)$ remained significant, and site became significant $(P=.04)$. Group was not significant for either BMI or waist $z$ score.

\section{Impact on Parenting}

Table 3 presents the parenting outcomes (mean \pm SD) and results of the linear mixed-model analysis. There was a significant time effect in 6 of 8 outcomes; scores improved from baseline to 6 months $(P<.05)$ and generally remained stable thereafter to 24 months. There was no group or time-by-group effect for any parenting outcome, indicating that changes were the same for both groups. There was a significant gender effect and/or gender-by-group effect for satisfaction, involvement, and positive parenting, and there were better scores for boys in the HL group compared with girls. No adverse events were reported.

\section{DISCUSSION}

This study evaluated the effectiveness of a healthy lifestyle intervention for overweight children aged 5 to 9 years presented to parents (agents of change) only. It also evaluated whether adding parenting skills training would enhance the effect of the lifestyle intervention. The key finding was that overall, a $10 \%$ relative weight loss was achieved by intervention end ( 6 months) and then maintained for a additional 18 months (ie, from 6 to 24 months' postintervention with no additional intervention). There was a weak effect on BMl z score of the addition of parenting skills at intervention end, but this group difference was lost over time.

Comparison of effect size in our study with other pediatric studies is hampered by variations in active and con- trol conditions, follow-up periods, and outcome measures. A recent metaanalysis ${ }^{11}$ reported changes in the percentage overweight of $-8.2 \%$ in treatment and $2.7 \%$ in control groups at intervention end. The 2009 Cochrane meta-analysis ${ }^{5}$ reports a mean difference in BMI $z$ score of -0.04 at 12 months' follow-up between lifestyle interventions and standard care in children younger than 12 years. On the basis of these data, our interventions were comparatively successful.

As yet, there are no data to determine the magnitude of relative weight loss in prepubertal children that is clinically significant. In adults, relative weight loss of the magnitude observed in this study is defined as successful ${ }^{34}$ and is associated with clinically relevant health benefits and risk reduction. ${ }^{35,36}$ The outcomes of our study of long-term maintenance of weight loss up to 18 months' postintervention are better than published adult outcomes ${ }^{34,35}$ and provide sound evidence for an investment in weight management of overweight prepubertal children as a secondary prevention strategy.

The 10\% reduction in BMI and waist size in both groups strongly supports previous studies showing that targeting parents as agents of change is an

TABLE 3 Parenting Outcomes (Mean \pm SD) at Each Assessment for the Total PEACH Sample and the Results of the Linear Mixed-Model Analysis

\begin{tabular}{|c|c|c|c|c|c|c|c|}
\hline $\begin{array}{c}\text { Parent Sense of } \\
\text { Competency }\end{array}$ & Items & Baseline $^{a}$ & $6 \mathrm{mo}$ & $12 \mathrm{mo}$ & $18 \mathrm{mo}$ & $24 \mathrm{mo}$ & Significance, $P^{b}$ \\
\hline Satisfaction ${ }^{\mathrm{C}}$ & 9 & $36.3 \pm 6.9$ & $39.1 \pm 5.9$ & $39.6 \pm 5.8$ & $40.3 \pm 7.3$ & $39.3 \pm 5.8$ & Time: $<.001^{c}$, gender by group: $0.05, \mathrm{~s}$ \\
\hline Efficacy ${ }^{d}$ & 7 & $28.3 \pm 5.8$ & $29.5 \pm 5.5$ & $30.2 \pm 5.1$ & $29.5 \pm 5.1$ & $30.1 \pm 5.2$ & Time: $<.001^{\mathrm{c}}$ \\
\hline Totald $^{\mathrm{d}}$ & 16 & $64.2 \pm 10.9$ & $68.5 \pm 10.0$ & $67.0 \pm 9.2$ & $69.6 \pm 9.8$ & $69.2 \pm 9.6$ & Time: $<.001^{\mathrm{c}}$ \\
\hline \multicolumn{8}{|l|}{ Alabama parentinge } \\
\hline Involvement ${ }^{\mathrm{d}}$ & 10 & $39.4 \pm 4.2$ & $39.6 \pm 4.3$ & $40.1 \pm 4.5$ & $39.5 \pm 5.1$ & $39.4 \pm 4.5$ & Time: .06, gender: .008, gender by group: $<.001$ \\
\hline Positive parentingd & 6 & $25.5 \pm 2.5$ & $25.4 \pm 2.7$ & $25.2 \pm 2.7$ & $25.0 \pm 2.6$ & $24.8 \pm 3.0$ & Time: .27 , gender: .005 , gender by group: .02 \\
\hline Poor monitoring ${ }^{f}$ & 10 & $12.6 \pm 2.8$ & $12.8 \pm 3.0$ & $12.0 \pm 2.0$ & $12.5 \pm 3.2$ & $12.2 \pm 2.5$ & Time: .13, age: .001 \\
\hline Inconsistent discipline ${ }^{f}$ & 6 & $15.5 \pm 3.5$ & $14.2 \pm 2.9$ & $13.6 \pm 2.9$ & $13.8 \pm 3.0$ & $13.9 \pm 3.1$ & $<.001^{\mathrm{c}}$ \\
\hline Corporal punishment ${ }^{f}$ & 3 & $5.1 \pm 1.6^{8}$ & $4.8 \pm 1.6$ & $4.1 \pm 1.3$ & $4.1 \pm 1.3$ & $3.8 \pm 1.2$ & $<.001^{\text {h }}$, site: .005 , gender: .012 , gender by group: .006 \\
\hline
\end{tabular}

\footnotetext{
a No differences according to group, all variables.

${ }^{\mathrm{b}}$ Linear mixed-model fixed effects; $P$ nonsignificant for all variables for group and group by time

${ }^{c}$ Linear mixed model: posthoc analysis (Bonferroni method), $P<.05$ for baseline versus all other times.

${ }^{\mathrm{d}}$ An increase in score indicates improvement.

e Alabama Parenting Questionnaire. ${ }^{28}$

${ }^{\mathrm{f}} \mathrm{A}$ decrease in score indicates improvement.

8 Linear mixed model: posthoc analysis (Bonferroni method), $P<.05$ for baseline versus all other times and 6 vs 12 and 24 months.

$\mathrm{h}$ Boys had a significantly higher score than girls; Sydney scores were significantly higher than those in Adelaide.
} 
effective strategy for weight management in young children both shortterm ${ }^{9,10}$ and long-term. ${ }^{37}$ The improvements in parenting outcomes observed in both groups suggest a mechanism for this reduction. Overall, there was a lack of group difference, which required us to reject the a priori hypothesis that parenting skills training improves the outcomes of a healthy lifestyle intervention for overweight children. However, the potential attrition bias favoring heavier children being lost to follow-up in the HL but not in the $\mathrm{P}+\mathrm{HL}$ intervention, and the nonlinear relationship between relative weight loss and time, are potential limitations that may have contributed to this lack of group difference. The analysis of data that included only baseline and immediate postintervention assessments identified a weak time-by-group interaction; greater changes occurred in the $\mathrm{P}+\mathrm{HL}$ than in the HL group.

The lack of group difference may be attributable to the generic nature of The Triple P program, which was designed to improve child disruptive behavior and dysfunctional parenting 38 and was not specific to obesity management. At the time we conducted the study, no such program was available. The Triple P was chosen because it was standardized, designed for group use in community and clinical settings, included facilitator training, and had been formally evaluated. ${ }^{22}$ It is possible that some strategies had limited relevance to parents in terms of targeting their child's eating and activity behaviors, and, despite healthy lifestyle examples used, parents may have had difficulty applying the strategies to eating and activity behaviors. The lack of group difference in parenting outcomes supports this. Inclusion of specific self-efficacy strategies explicitly aimed at parents themselves to enhance their capacity to implement recommended changes to their parenting behavior may result in better outcomes in the $\mathrm{P}+\mathrm{HL}$ intervention, which also extend beyond intervention end. ${ }^{39}$ It is possible that the additional 4 sessions in the $\mathrm{P}+\mathrm{HL}$ group may have contributed to the modest group effect at the end of the intervention. However, both programs aimed to effect small but cumulative changes in family lifestyle over the length of the intervention (ie, 6 months), which was the same for both groups. Given the chronic nature of obesity, the many behaviors associated with the condition, and the variable attendance, we believe this is an unlikely explanation for the group difference.

Strengths of the study include the large sample size, adjustment for significant covariates, and follow-up to 18 months' posttreatment. The bestpractice interventions used are both sustainable in usual health care settings and consistent with current evidence and clinical guidelines. ${ }^{6-8} \mathrm{Ad}$ herence and retention $(80 \%$ at 6 months and $60 \%$ at 2 years) were well documented, acceptable in clinical practice, and consistent with other weight-management trials in this age group, ${ }^{5}$ and the effect of missing data were investigated. ${ }^{33}$ Study results are generalizable to families who recognize that their child is overweight and are willing to seek treatment, and generalizability is enhanced by the dualsite design and multiple facilitators.

Our study design does not preclude similar treatment and maintenance effects in a no-treatment control group. However, this seems unlikely on the basis of results from a recent metaanalysis showing an average increase in the percentage overweight of $2.1 \%$ and $2.7 \%$ at the end of treatment and postintervention follow-up periods, respectively, for no-treatment or information-only control groups. ${ }^{11}$ We believed that, having recruited obese children and their families, offering no intervention or wait-listing for 2 years was unethical and, furthermore, likely to result in substantial attrition in the control group with substantial threats to internal validity.

of interest is the greater reduction in waist $z$ score in boys, which confirms our previous findings. ${ }^{16}$ Other studies support this finding, ${ }^{40}$ better outcomes for girls, ${ }^{41}$ or no gender effect,, 64 whereas a reanalysis of 8 efficacy randomized controlled trials showed that girls had substantially better BMI $z$ score outcomes at 5 to 10 years, largely because of a much greater relapse effect in boys. ${ }^{43}$ The direction of gender differences in relative weight loss and the underlying predictive factors are worthy of future study to optimize clinical intervention.

\section{CONCLUSIONS}

Overall, this study demonstrates that a relative weight loss of $\sim 10 \%$ is achievable and can be maintained for up to 2 years in moderately obese prepubertal children and provides support for a parent-only approach. This weight loss was achieved with an overall investment equivalent to 2.5 hours of therapist time per family over the 2 years and, hence, is sustainable and less costly than individual treatment and follow-up, which are of uncertain effectiveness. There is some suggestion that the addition of parenting skills training may improve short-term treatment outcomes, but this group effect was not maintained. A key question is whether more comprehensive parenting skills training developed specifically to support lifestyle changes, maintenance treatment strategies, and ongoing therapist contact to ensure longer-term application of the newly acquired parenting skills, consistent with a chronic condition approach, would maintain both the group effect and the ongoing relative weight loss seen at the end of the treatment pro- 
gram. These results provide justification and encouragement for clinicians and administrators to invest in treatment of moderately obese children as an effective secondary obesityprevention strategy.

\section{ACKNOWLEDGMENTS}

This research was primarily funded by Australian National Health and Medical Research Council grant 275526. Addi-

\section{REFERENCES}

1. Wang $Y$, Lobstein $T$. Worldwide trends in childhood overweight and obesity. Int J Pediatr Obes. 2006;1(1):11-25

2. Wake M, Hardy P, Canterford L, Sawyer M, Carlin JB. Overweight, obesity and girth of Australian preschoolers: prevalence and socio-economic correlates. Int $J$ obes (Lond). 2007;31 (7):1044-1051

3. Reilly JJ, Methven E, McDowell ZC, et al. Health consequences of obesity. Arch Dis Child. 2003;88(9):748-752

4. World Health Organization. Obesity: Preventing and Managing the Global Epidemic: Report of a WHO Consultation on Obesity. Geneva, Switzerland: World Health Organization; 1998

5. Oude Luttikhuis H, Baur L, Jansen $H$, et al. Interventions for treating obesity in children. Cochrane Database Syst Rev. 2009; (1):CD001872

6. National Health and Medical Research Council. Clinical Practice Guidelines for the Management of Overweight and Obesity in Children and Adolescents. Canberra, Australia: Commonwealth of Australia; 2003

7. National Institute for Health and Clinical Excellence. Obesity: Guidance on the Prevention, Identification, Assessment and Management of Overweight and Obesity in Adults and Children. London, United Kingdom: National Institute for Health and Clinical Excellence; 2006

8. American Dietetic Association. Position of the American Dietetic Association: individual-, family-, school-, and communitybased interventions for pediatric overweight. J Am Diet Assoc. 2006;106(6): 925-945

9. Golan M, Kaufman V, Shahar D. Childhood obesity treatment: targeting parents exclusively v. parents and children. $\mathrm{Br} J$ Nutr. 2006;95(5):1008-1015

10. Golan M, Weizman A, Apter A, Fainaru M. Parents as the exclusive agents of change in tional funding was provided by the New South Wales Centre for Overweight and Obesity. Dr Perry was supported by a National Health Foods Australia Postgraduate scholarship and an Australian National Health and Medical Research Council postgraduate research scholarship (grant 375184). The funding sources had no role in the design, implementation, analysis, or interpretation of this study or in writing the report or the decision to submit.

the treatment of childhood obesity. Am J Clin Nutr. 1998;67 (2):1130-1135

11. Wilfley DE, Tibbs TL, Van Buren DJ, Reach KP, Walker MS, Epstein LH. Lifestyle interventions in the treatment of childhood overweight: a meta-analytical review of randomized controlled trials. Health Psychol. 2007;26(5):521-532

12. Kitzmann K, Beech B. Family-based interventions for pediatric obesity: methodological and conceptual challenges from family psychology. J Family Psychol. 2006;20(2): 175-189

13. Ventura AK, Birch LL. Does parenting affect children's eating and weight status? Int J Beh Nutr Phys Act. 2008;5:15-44

14. Patrick H, Nicklas TA, Hughes SO, Morales M. The benefits of authoritative feeding style: caregiver feeding styles and children's food consumption patterns. Appetite. 2005;44(2): 243-249

15. Rhee KE, Lumeng JC, Appuǵliese DP, Kaciroti $\mathrm{N}$, Bradley RH. Parenting styles and overweight status in first grade. Pediatrics. 2006;117 (6):2047-2054

16. Golley RK, Magarey AM, Baur LA, Steinbeck KS, Daniels LA. Twelve-month effectiveness of a parent-led, family-focused weightmanagement program for prepubertal children: a randomized controlled trial. $P e-$ diatrics. 2007;119(3):517-525

17. Cole TJ, Bellizzi MC, Flegal KM, Dietz WH. Establishing a standard definition for child overweight and obesity worldwide: international survey. BMJ. 2000;320(7244):1-6

18. Tanner J. Growth at Adolescence: With a General Consideration of the Effects of Hereditary and Environmental Factors Upon Growth and Maturation From Birth to Maturity. 2nd ed. Oxford, United Kingdom: Blackwell Scientific Publications; 1962

19. Moher D, Schulz KF, Altman DG. The CONSORT statement: revised recommendations for improving the quality of reports of parallel-
We thank the children and families for participating in the study. We also thank the following for their assistance: staff in Adelaide and Sydney who facilitated the activity sessions; Amanda Johnson and Christina Brown, who facilitated the HL sessions in Sydney; Ms Kylie Lange and Mr Pawel Skuza for statistical advice and support; and Ms Bunni Franco, who audited the sessions.

group randomised trials. Lancet. 2001; 357 (9263):1191-1194

20. Golan M, Crow S. Parents are key players in the prevention and treatment of weightrelated problems. Nutr Rev. 2004;62(1): $39-50$

21. Golley RK, Perry RA, Magarey AM, Daniels LA. Family-focused weight management program for five- to nine-year olds incorporating parenting skills training with healthy lifestyle information to support behaviour modification. Nutr Diet. 2007;64(3):144-150

22. Turner KMT, Markie-Dadds C, Sanders MR. Facilitator's Manual for Group Triple P. 2nd ed. Brisbane, Australia: Families International Publishing Pty Ltd; 2000

23. Trewin D. Socio-economic Indexes for Areas (SEIFA). Canberra, Australia: Australian Bureau of Statistics; 2001

24. Norton KI, Whittingham N, Carter JEL, Ker D, Gore C, Marfell-Jones MJ. Measurement techniques in anthropometry. In: Norton KI, Olds TS, eds. Anthropometrica. Sydney, Australia: University of New South Wales Press; 1996:25-75

25. Cole TJ, Freeman JV, Preece MA. Body mass index reference curves for the UK, 1990. Arch Dis Child. 1995;73(1):25-29

26. McCarthy HD, Jarrett KV, Crawley HF. The development of waist circumference percentiles in British children aged 5.0-16.9 y. Eur J Clin Nutr. 2001;55(10):902-907

27. Johnston C, Mash EJ. A measure of parenting satisfaction and efficacy. J Clin Child Psychol. 1989;18(2):167-175

28. Shelton KK, Frick PJ, Wootton J. Assessment of parenting practices in families of elementary school-age children. J Clin Child Psychol. 1996;25(2):317-329

29. Summerbell CD, Ashton V, Campbell KJ, et al. Interventions for treating obesity in children. Cochrane Database Syst Rev. 2003; (3): CD001872

30. Warren JM, Golley RK, Collins CE, et al. Ran- 
domised controlled trials in overweight children: practicalities and realities. Int $J$ Pediatr Obes. 2007;2(2):73-85

31. West BT, Welch KB, Galecki AT. Models for clustered longitudinal data: the dental veneer example. In: Linear Mixed Models: A Practical Guide Using Statistical Software. Boca Raton, FL: Chapman and Hall/CRC Press; 2006:327-328

32. Krueger C, Tian L. A comparison of the general linear model and repeated measures ANOVA using a dataset with multiple missing data points. Biol Res Nurs. 2004;6(2):151-157

33. Hollis $\mathrm{S}$, Campbell F. What is meant by intention to treat analysis? Survey of published randomised controlled trials. BMJ. 1999; 319(7240):670-674

34. Wing RR, Hill J0. Successful weight loss maintenance. Annu Rev Nutr. 2001;21: 323-341
35. National Health and Medical Research Council. Clinical Practice Guidelines for the Management of Overweight and Obesity in Adults. Canberra, Australia: Commonwealth of Australia; 2003

36. Knowler WC, Barrett-Connor E, Fowler SE, et al. Reduction in the incidence of type 2 diabetes with lifestyle intervention or metformin. N Engl J Med. 2002;346 (6):393-403

37. Golan M, Crow S. Targeting parents exclusively in the treatment of childhood obesity: long-term results. Obes Res. 2004;12(2):357-361

38. Morawska A, Sanders MR. Concurrent predictors of dysfunctional parenting and maternal confidence: implications for parenting interventions. Child Care Health Dev. 2007;33(6):757-767

39. Bandura A. Self efficacy: toward a unifying theory of behaviour change. Psychol Rev. 1977;84(2):191-215
40. Epstein LH, Paluch RA, Raynor HA. Gender differences in obese children and siblings in family-based obesity treatment. Obes Res. 2001;9(12):746-753

41. Kalavainen MP, Korppi MO, Nuutinen OM. Clinical efficacy of group-based treatment for childhood obesity compared with routinely given individual counseling. Int J Obes (Lond). 2007;31(10):1500-1508

42. Reinehr T, Temmesfeld M, Kersting M, de Sousa G, Toschke AM. Four-year follow-up of children and adolescents participating in an obesity intervention program. Int J Obes (Lond). 2007;31(7):1074-1077

43. Epstein LH, Paluch RA, Roemmich JN, Beecher MD. Family-based obesity treatment, then and now: twenty-five years of pediatric obesity treatment. Health Psychol. 2007;26(4):381-391

ALCHEMY: While visiting a friend, I noticed that his son was reading a book from school entitled Alchemy. Who in the world studies alchemy, I wondered. It turns out that plenty of famous individuals, including Isaac Newton did. According to an article in The New York Times (Angier N, October 11, 2010), Newton, the famous physicist, mathematician, and astronomer was consumed by the study of alchemy. Newton may actually have spent more time studying alchemy than the natural sciences. Alchemy, the changing of one substance into another (and not just into gold), was an accepted theory by most scientists of the $17^{\text {th }}$ century. After all, iron bars dipped into specific spring waters became sheathed in copper. The alchemist theory that substances are made of invisible and indivisible subcomponents that can be rearranged into more complex substances sounds a lot like what we learned in high school. Lacking a particle accelerator, however, alchemists such as Newton were not successful in altering substances. However, their studies were not without merit as their discoveries led to improved painting pigments, new medications and soaps and the development of chemistry as a field of study. The study of alchemy may have helped Newton develop his theory of optics in which light can be divided into a combination of colors and then the colors recombined. While Newton believed in particles or corpuscles rather than waves, the concept that light could be divided remains intact. While the history of alchemy has been populated by charlatans, Newton was an empiricist and intolerant of fraud. The next time I go to a "chemist" in England to fill a prescription, I will know that the term comes from "alchemy". Interesting. 


\section{A Parent-Led Family-Focused Treatment Program for Overweight Children Aged 5 to 9 Years: The PEACH RCT}

Anthea M. Magarey, Rebecca A. Perry, Louise A. Baur, Katharine S. Steinbeck, Michael Sawyer, Andrew P. Hills, Gizelle Wilson, Anthea Lee and Lynne A. Daniels Pediatrics 2011;127;214; originally published online January 24, 2011; DOI: $10.1542 /$ peds. 2009-1432

\section{Updated Information \& Services}

References

Citations

\section{Subspecialty Collections}

Permissions \& Licensing

Reprints including high resolution figures, can be found at: http://pediatrics.aappublications.org/content/127/2/214.full.ht $\mathrm{ml}$

This article cites 32 articles, 8 of which can be accessed free at:

http://pediatrics.aappublications.org/content/127/2/214.full.ht ml\#ref-list-1

This article has been cited by 3 HighWire-hosted articles: http://pediatrics.aappublications.org/content/127/2/214.full.ht ml\#related-urls

This article, along with others on similar topics, appears in the following collection(s):

Office Practice

http://pediatrics.aappublications.org/cgi/collection/office_pra ctice

Information about reproducing this article in parts (figures, tables) or in its entirety can be found online at:

http://pediatrics.aappublications.org/site/misc/Permissions.xht $\mathrm{ml}$

Information about ordering reprints can be found online: http://pediatrics.aappublications.org/site/misc/reprints.xhtml

PEDIATRICS is the official journal of the American Academy of Pediatrics. A monthly publication, it has been published continuously since 1948. PEDIATRICS is owned, published, and trademarked by the American Academy of Pediatrics, 141 Northwest Point Boulevard, Elk Grove Village, Illinois, 60007. Copyright @ 2011 by the American Academy of Pediatrics. All rights reserved. Print ISSN: 0031-4005. Online ISSN: 1098-4275.

\section{American Academy of Pediatrics}

